\title{
PSYCHOSOSIAL STIMULATION IN STUNTING AND NON STUNTING FIRMS
}

\author{
Dian Rahmawati, Lia Agustin \\ Academy of Midwifery of Dharma Husada Kediri
}

\begin{abstract}
Background: Stunting is a condition of growth failure among children under five due to chronic malnutrition. According to World Health Organization (WHO), stunting under five is a public health problem if the prevalence is $20 \%$ or more. In 2018, stunting in Indonesia is more than 20\%, so it becomes a public health problem and needs to be addressed immediately. Stunting does not only affect physical growth but also psychosocial development. Stunting can reduce the quality of human resources (HR) because the body's organs, especially the brain, are not able to develop optimally, and increase the risk of diseases such as hypertension, diabetes mellitus, heart disease, and stroke. The low psychosocial stimulation has an impact on the subsequent growth of the child. This study aimed to analyze the association between psychosocial stimulation and stunting.

Subjects and Method: A case control study was conducted in the Village Bangkok, Kediri, East Java, in August 2020. A total sample of 25 stunting children aged 24-59 months was obtained as a case group and 25 normal toddlers aged 24-59 months as a control group. The dependent variable was the incidence of stunting, while the independent variable was psychosocial stimulation. The stunting measurement was based on the height per age (converted into a Z-score). Measurement of psychosocial stimulation was using the Home Observation for Measurement of the Environment Revisited (HOME) questionnaire consists of 55 statements divided into 8 aspects. The data were collected and analyzed using the Chi Square test.

Results: Stunting children showed that psychosocial stimulation were low (20\%), medium (64\%), and high (16\%). While psychosocial stimulation among not stunted children were absent (0\%), medium (64\%), and high (36\%). Psychosocial stimulation was associated with the incidence of stunting $(\mathrm{p}=0.031)$, and it was statistically significant.

Conclusion: Psychological stimulation is associated with the incidence of stunting. The psychosocial stimulation provided by families for stunting toddlers is still less than that of nonstunting children.
\end{abstract}

Keywords: stunting, psychosocial stimulation, children under five

\section{Correspondence:}

Dian Rahmawati. Academy of Midwifery of Dharma Husada. Jl. Penanggungan 41A Kediri City 64114, East Java. Email: lintangkayana31@gmail.com. Mobile: +6285645076003 